Ana B. Mandić Ivković*

Beogradska poslovna škola https://doi.org/10.18485/analiff.2018.30.1.4

821.09:78

Originalni naučni rad

Primljen: 02.04.2018.

Prihvaćen: 10.07.2018.

\title{
ADAPTACIJA I INTERTEKSTUALNOST
}

U studijama filmske adaptacije, teorije intertekstualnosti dobijaju sve veći značaj, naročito u poslednje dve decenije. Ovaj rad zasniva se na teorijskom pristupu filmskoj adaptaciji gde se kritički predstavljaju teorije Thomasa Leitcha, Linde Hutcheon, Mikhaila Bakhtina, Roberta Stama, Christiana Metza, Briana McFarlana, Linde Cahir, Katje Krebs i drugih značajnih teoretičara. U ovom radu analizira se odnos procesa adaptacije i procesa prevođenja i zaključuje da filmska umetnost poseduje vlastiti filmski jezik i filmski narativ, jer film poput književnog dela, takođe pripoveda priču koristeći drugačija sredstva izražavanja. Adaptacija konkretizuje i aktualizuje određene ideje, pravi izbor i analogije, izražava kritiku ili ukazuje poštovanje originalnom tekstu. Adaptaciju sagledavamo kao formalni entitet i kao transpoziciju određenog književnog dela, pri tom imajući u vidu promenu medija, eventualnu promenu žanra, promenu okvira ili konteksta, promenu tačke gledišta u okviru nove interpretacije. Analiziramo teorijski pristup adaptaciji kao slobodnom prevodu postojećeg teksta na nove jezike, i kritički zaključujemo da adaptacija predstavlja stvaralački proces, koji sam po sebi podrazumeva novu interpretaciju i čin stvaranja novog umetničkog dela. U tom stvaralačkom procesu osnovna premisa je da se sačuva priča preuzeta iz originalnog književnog dela ali da se njoj istovremeno udahne novo viđenje koje će uspešno komunicirati sa publikom. Adaptacija je forma intertekstualnosti. Ona je višeslojna i u sebi nosi kako repeticiju originalnog izvornog teksta tako i varijacije novog umetničkog stvaralaštva.

Ključne reči: intertekstualnost, teorija vernosti, dijalogizam, prevod, filmski jezik, filmski narativ

Linda Hačen (Linda Hutcheon) u svom delu Teorija Adaptacije (Theory of Adaptation) adaptaciju definiše kao: ,produženu, planiranu i najavljenu ponovnu posetu određenom umetničkom delu" (Leitch, 2012: 87), postavljajući zapravo pitanje: šta je to što ne predstavlja adaptaciju - koja vrsta interteksta se može smatrati adaptacijom a koja ne? Ono što Hačen naziva „,pravilnom adaptacijom” (adaptation proper) su one vrste

*_anamandic73@gmail.com 
stvaralaštva koje svoju estetiku prvenstveno zasnivaju na vernosti originalnom tekstu (2012: 87). Stoga se nameću pitanja: da li se svako izvođenje ili svaki kritički komentar može smatrati adaptacijom? Koja je razlika između interteksta i adaptacije? Šta se može smatrati adaptacijom a šta prisvajanjem ili aproprijacijom? (2012: 88). Džuli Sanders (Julie Sanders) to objašnjava na sledeći način:

Adaptacija označava vezu sa izvornim tekstom ili originalom. S druge strane aproprijacija često predstavlja odlučniji način udaljavanja od datog teksta ka potpuno novom proizvodu ili oblasti kulture. Ovo može i ne mora uključiti generičku promenu, i može zahtevati upoređivanje jednog teksta naspram drugog....ali prisvojeni tekst ili tekstovi nisu uvek jasno označeni ili priznati kao što je to u procesu adaptacije. Oni se mogu naći u manje jasnom ili manje očiglednom kontekstu nego što je to slučaj sa filmskom verzijom neke kanonske drame (Leitch, 2012: 88).

Lič se slaže sa stavom Linde Hačen da se adaptacija zasniva na „kontinumu intertekstualnih odnosa" (2012: 88). Takođe Lič postavlja pitanje gde povući granicu između odgovarajuće i neodgovarajuće adaptacije, i koja bi uopšte bila svrha povlačenja ovakvih granica. Lič polazi od aksioma da je ,adaptacija zbirka intertekstualnosti - jer su sve adaptacije očigledno intertekstovi, ali je daleko manje očigledno da su svi intertekstovi adaptacije" (2012: 89). Stoga Lič iznosi devet tačaka koje govore u prilog odnosu između adaptacije i intertekstualnosti:

1. Adaptacije su isključivo kinematografske, uključujući samo filmove nastale po romanima, dramama ili pripovetkama (2012: 89).

Ovakav stav u studijama adaptacije bio je dominantan punih četrdeset godina, tačnije od 1957. godine i objavljivanja dela Romani na filmu (Novels into Film) Džordža Blustouna (George Bluestone) pa sve do 1999. godine i izdanja Adaptacije: od teksta do ekrana, od ekrana do teksta (Adaptations: From Text to Screen, Screen to Text) čiji su urednici Debora Kartmel (Deborah Cartmell) i Imelda Vilehan (Imelda Whelehan). U ovoj publikaciji proširen je dijapazon intertekstualnosti te se adaptacijom smatra i televizijski program, kao i filmovi nastali na osnovu stripova, čak i filmovi poput Klavira koji odaju utisak filmske adaptacije iako to zapravo nisu. Kartmel i Vilehan suprostavljaju se prvobitnoj ideji da su „književne adaptacije jednosmerni prevodi klasičnih tekstova na ekran” (2012: 89). 2008. godine osniva se Udruženje studija adaptacije gde se pristupa adapta- 
cijama na bimedijalan način te se kinematografski i televizijski tekstovi scenarija analiziraju u odnosu na njihove književne originale. Ovakav pristup ima značajna ograničenja, jer u vremenu neverovatne medijske ekspanzije, ne razmatra adaptacije drugih medija poput opere, baleta, pozorišnih predstava, web strana, you tube videa koji se zasnivaju na ranijim tekstovima zapravo, izučava se samo film kao medij (2012: 90).

2. Adaptacije su isključivo intermedijske, jer uključuju transfer narativnih elemenata sa jednog medija na drugi (2012: 91).

Ovakav model ima prednost u odnosu na prvi jer medije koji su u interakciji ne definiše isključivo kao književne i filmske. Američka akademija filmskih umetnosti i nauka od 1958. godine pravi jasnu razliku u dodeli Oskara za najbolji originalni scenario i Oskara za najbolji adaptirani scenario koji se zasniva na materijalu drugih medija. Adaptirani scenario se može zasnivati na romanima, dramama, pripovetkama, operama, baletima, stripovima, video igrama i popularnim pesmama. Lič smatra da intermedijalni model omogućava neutralniji pristup pri evaluaciji neke adaptacije.

3. Adaptacije su kontra - ekfraze (2012: 93).

Termin ekfraza je antički naziv za slikovito opisivanje. Ovakav model zauzima stav da je književnost inferiorna u odnosu na vizuelne umetnosti, jer je autoru potrebno mnoštvo reči da sa mukom dočara ono što može da ostvari moć slike (2012: 93). Adaptacija, zahvaljujući svojoj hibridnoj formi reči i slike, može snažnije da dočara određeno iskustvo, koje se pisanom reči tek naslućuje.

4. Adaptacije su tekstovi čiji status se zasniva na namernom pozivu publici da im pristupi kao adaptacijama (2012: 95).

S obzirom da se rimejk nekog filma može zasnivati na prethodnom filmskom ostvarenju ili pak na književnom izvoru, nameće se problem intertekstualnosti, jer ako analiziramo filmsko ostvarenje Psiho Gusa Van Santa iz 1998. godine, postavlja se pitanje da li ga posmatramo kao rimejk filma Alfreda Hičkoka iz 1960. godine ili kao adaptaciju romana Roberta Bloka (2012: 95). U ovakvom procesu kontekstualizacije najvažnije bi bilo analizirati intertekstove koji se ističu u datoj adaptaciji. 
5. Adaptacije su jasni primeri modela transtekstualnosti (2012: 96).

Lič predstavlja pet modela transtekstualnosti:

a) intertekstualnost označena citatima i aluzijama;

b) paratekstualnost naznačena sekundarnim odrednicama kao što su naslovi, predgovori, epigrafi;

c) metatekstualnost komentara i aluzije;

d) arhitekstualnost implicitno prisutna u paratekstualnosti;

e) hipertekstualnost koja povezuje jedan tekst sa hipotekstom (2012: 96).

Od svega nabrojanog Robert Stem (Robert Stam) smatra da je hipertekstualnost najvažnija za adaptaciju. Ovih pet kategorija transtekstualnosti ne treba posmatrati kao odvojene i nezavisne jer se one neprestano uzajamno prepliću. Nemoguće je povući jasnu granicu između hiperteksta i hipoteksta ,jer svaki pisani tekst koji sledi funkcioniše kao hipertekst u odnosu na svog prethodnika, ali istovremeno i kao hipotekst u odnosu na onaj koji iza njega sledi” (2012: 97). Hipertekstualna derivacija ima dva osnovna tipa: transformaciju i imitaciju. Hipertekstovi često moraju odgovoriti zahtevima društva, jer većina filmskih adaptacija teži kako umetničkom tako i komercijalnom uspehu.

6. Adaptacije su prevodi (2012: 97).

Blustoun, međutim, pravi jasnu razliku između ova dva termina:

Dok se često filmovi zasnovani na književnosti nazivaju adaptacijama, sama reč „adaptirati” ima značenje promeniti strukturu ili funkciju entiteta kako bi lakše preživeo i razmnožavao se u novoj sredini. Adaptirati značilo bi taj isti entitet postaviti u novu sredinu. U procesu adaptacije, isti nezavisan entitet koji je ušao u sam proces, postoji, iako je podvrgnut modifikaciji - ponekad i radikalnoj mutaciji - u svojim naporima da se prilagodi novoj sredini.

„Prevoditi”, nasuprot „adaptirati”, znači prevesti tekst sa jednog jezika na drugi. To je jezički proces, a ne proces opstanka i stvaranja. Procesom prevođenja potpuno novog teksta stvara se materijalno različit entitet, koji istovremeno ima jak odnos sa originalnim tekstom, a ipak je od njega nezavisan. Jednostavno rečeno: mi smo u mogućnosti da čitamo i razumemo prevod bez čitanja originalnog izvora (2012: 98). 
Linda Kahir (Linda Cahir) pak smatra da adaptacije nisu doslovni prevodi ali da je ,,svaki čin prevođenja zapravo istovremeno čin interpretacije" (2012: 98).

7. Adaptacije su predstave (2012: 99).

Ako bi se pošlo od stanovišta da su adaptacije interpretacije mogao bi se zauzeti stav da su ujedno i predstave mada ni jedan teoretičar ne daje ovakvu definiciju. Filmske adaptacije su predstave koje se zasnivaju na scenarijima, mada Džek Buzer (Jack Boozer) kaže: ,da je scenario samo osnovni nacrt za adaptirani film te stoga nije vredan ozbiljnog razmatranja" (2012: 100).

8. Adaptacije su kvintesencijski primeri intertekstualne prakse (2012: 100).

Adaptacija nastaje kao verzija ranijeg teksta i ima status hibridnog medija. Džon Tibets (John Tibbetts) i Džejms Velš (James Welsh) smatraju da adaptacija predstavlja dihotomiju tekstova, tekstualnosti i kulturnog statusa jer ona obuhvata ,umetnost i trgovinu, individualnu kreativnost i zajedničku tvorevinu, kulturu i masovnu kulturu, verbalno i vizuelno"(2012: 101).

9. Adaptacije su istaknuti primer, ali ne i centralni ili kvintesencijski primer intertekstulnosti (2012: 102).

Ovakvo tumačenje u potpunoj je suprotnosti sa prethodnim modelom. Linda Hačen kaže:

Iako postoji potreba za proširenjem koncepta adaptacije kako bi uključili prošireno „refunkcionisanje” (kako ga nazivaju ruski formalisti) kao karakteristiku umetnosti našeg doba, mi istovremeno moramo da ograničimo njen fokus u smislu da je „ciljni” tekst adaptacije uvek neko drugo umetničko delo, uopšteno gledajući, drugi oblik kodiranog diskursa (2012: 102).

Mi takođe uočavamo da postoji i druga vrsta adaptacije....Ta druga vrsta ili model ima širi okvir pragmatičnog etosa, njegova forma je značajno šira. Adaptacija u umetnosti dvadesetog veka je glavni model tematskog i formalnog strukturiranja, što uključuje, ono što sam ranije nazvala integrisanim procesima modelovanja. Kao takva, jedna je od najčešćih formi tekstualnog samoposmatranja našeg doba. Označava ukrštanje stvaralaštva i ponovnog stvaralaštva, pronalaska i kritike (2012: 102). 
Pre Bahtinove teorije, postojali su različiti pristupi teoriji adaptacije pa su strukturalisti svoju studiju adaptacije zasnivali na stavu da svaki adaptirani tekst treba rastaviti na manje delove i zatim ga detaljno proučavati, što je zbog svoje kompleksnosti pojedine teoretičare dovelo do toga da se adaptaciji pristupa isključivo intertekstualno. Bahtinove ideje o intertekstualnosti su primenjive u studijama adaptacije. Međutim on smatra da se značenje ne može svesti samo na nivo reči izdvojene kao takve, već da se ona mora posmatrati u odnosu na druge reči koje u svojoj međusobnoj interakciji stvaraju mrežu raznih značenja koju mi čujemo ili izgovaramo (Cutchins, 2014: 43).

Živ govor, koji dobija značenje i oblik u određenom istorijskom trenutku u određenoj društvenoj sredini, ne može a da se ne suoči sa hiljadama niti živog dijaloga, koje tka društveno-ideološka svest oko datog objekta govora; ne može a da ne postane aktivni učesnik društvenog dijaloga. Povrh svega, govor proizilazi iz ovog dijaloga kao njegov nastavak i kao odgovor na odgovor - a ne prilazi objektu posredno (2014: 44).

Intertekstualnost polazi od stanovišta da sva značenja, uključujući i ona proizašla iz adaptacija, postaju deo ove kompleksne mreže. Bahtin smatra da je adaptacija zapravo nameran uticaj jednog teksta na drugi i da mi kao publika uživamo u adaptaciji posmatrajući to međusobno ukrštanje tekstova, njihov odnos, sličnosti i razlike, uviđajući mnoštvo značenja (2014: 44). On smatra da su književni tekstovi prepuni značenja i da svaka vrsta interpretacije ili adaptacije teksta, stvara čitavo mnoštvo namernih ili nenamernih novih značenja dok mi kao publika uzimamo aktivno učešće u njihovom tumačenju. Adaptacija istovremeno ima blizak odnos sa izvornim tekstom ali i sa realnim svetom u kome nastaje i u tome leži njena moć jer ona spaja često različite kulture, ideologije ili društvene prilike (2014: 50). Studije adaptacije podrazumevaju proučavanje tih međusobno povezanih tekstova i njihovih konteksta.

Studije adaptacije uvek se iznova vraćaju teoriji ,vernosti” što ne iznenađuje ako uzmemo u obzir da su prvi filmovi upravo nastali kao pokušaj da se vizuelno na filmskom platnu dočara stvarnost što je bio jedini kriterijum uspešnosti filma kod publike. Kada govorimo o teoriji „,vernosti” kod adaptacije pojam vernosti se odnosi pre svega na izvorni tekst po principu što je adaptacija bliža mom doživljaju originalnog teksta to je uspešnija. Ali Bahtinovo viđenje otvara novu problematiku jer moj doživljaj i viđenje ori- 
ginalnog teksta ne mora se podudarati sa tuđim doživljajem. Bahtin smatra da adaptacija u procesu prevođenja originalnog dela na novi medij ne gubi na vernosti, niti doprinosi uništenju ili deformaciji originalnog teksta, već naprotiv predstavlja kreativan proces stvaranja nove umetnosti. On se ne suprotstavlja direktno teoriji ,,vernosti” kao takvoj već odstupanje od originala vidi kao neizbežan i produktivan proces. $U$ tom procesu neka značenja se gube ali se istovremeno stvara mnoštvo novih značenja i stoga je adaptacija kao čin prevođenja književnog teksta na film kreativan proces koji stvara novu vrstu umetnosti (2014: 52).

Bahtin veruje u jezik ,koji ne predstavlja sistem apstraktnih gramatičkih kategorija, već jezik koji se poima kao ideološki zasićen, jezik kao pogled sveta“" (2014: 53); zapravo naše lično viđenje i poimanje sveta je neraskidivo povezano sa našim jezikom. Stoga Bahtin smatra da svako umetničko delo odražava različite poglede, jer svaki lik nekog romana ili drame zapravo govori različitim osobenim jezikom koji sa sobom donosi različito viđenje sveta. „Svi jezici heteroglosije, kakav god princip se nalazio u njihovoj osnovi i činio ih jedinstvenim, predstavljaju određene poglede na svet, forme konceptualizacije sveta kroz reči, specifične poglede na svet od kojih svaki karakterišu vlastiti ciljevi, značenja i vrednosti“" (2014: 54). Bahtin takođe navodi da jezik kojim govore likovi u romanima je ,verbalno i semantički autonoman; govor svakog lika poseduje vlastiti sistem verovanja, jer je svaki govor tuđi i na tuđem jeziku, te se stoga tako prelamaju namere samog autora" (2014: 54). Na taj način istovremeno se prelamaju dve različite namere, direktne namere samih likova, sa namerama njihovih autora. Bahtin je smatrao da je heteroglosija karakteristična za romane ali i za druga umetnička dela poput drame ili filma, itd. Svaki tekst uspešno stvara svoj jezik koji sadrži heteroglosiju a stoga i intratekstualni dijalog. Za studije adaptacije to znači da svaka adaptacija nekog teksta koja uključuje heteroglosiju mora imati i svoju tačku gledišta. Stoga Bahtinov pristup adaptaciji polazi od toga da je tačka gledišta glavna karakteristika svake adaptacije a ne njen periferni element (2014: 55).

Bahtin takođe uvodi i pojam hronotopa. To je mehanizam pomoću koga se realnost asimiluje u umetnost. Hronotop se definiše kao suštinska uzajamnost vremenskih i prostornih odnosa, onako kako su oni umetnički dati u književnosti. Hronotop daje predstavu o modelu kulture u kome je delo nastalo. Svi apstraktni elementi romana, od filozofskih do socijalnih, kroz njega ostvaruju konkretizaciju. Od velikog je značaja za književno 
delo, jer stoji u osnovi formiranja sižea, a svako neopravdano odstupanje od datog vremena ili prostora, narušava strukturu dela i otežava praćenje zbivanja. Bez datog vremena i prostora mi ne možemo pojmiti suštinu umetničkih ideja (2014: 58).

Bahtinove ideje pružaju okvire studijama adaptacije. On smatra da tekstovi ostvaruju svoje značenje i dobijaju na značaju tek kada dođu u kontakt sa drugim tekstovima, što donekle definiše adaptaciju a ipak joj pruža mogućnost da izbegne zamke koje nameće teorija ,vernosti”. Neizbežno, čitanje ovakvih tekstova navodi nas na uočavanje sličnosti i razlika, a istovremeno nam pruža mnoštvo namernih i nenamernih značenja. Sama adaptacija ne mora da usvoji sva značenja originalnog teksta ali ona neminovno svojim procesom stvara i unosi nova značenja sa kojima se mi kao publika susrećemo (2014: 59).

\section{Adaptacija kao intertekstualni dijalogizam}

Kada govorimo o filmskim adaptacijama romana, uvek se iznova vraćamo na ideju vernosti originalu i ukoliko adaptacija odstupa od osnovnog narativa fabule, kako tematski tako i estetski, to kod nas često dovodi do razočarenja. Adaptacija često može izostaviti one delove romana koji su po nama važni, ili pak vizuelni filmski prikaz može u potpunosti odstupati od slike kakvu smo mi stvorili u našoj mašti. Postavlja se pitanje da li adaptacija uopšte može ostati u potpunosti verna originalu usled promene medija?

Kritika vernosti vremenom se razvijala u dva pravca: prvi koji je smatrao da adaptirano delo mora ostati u potpunosti verno originalnom tekstu i drugi pravac koji polazi od toga da adaptacija treba da ostane verna duhu originalnog dela. Robert Stem smatra da ideja vernosti jeste od velikog značaja u odnosima ova dva medija. On smatra da se često polazi od pretpostavke da je roman taj koji sadrži suštinsko značenje koje je prikriveno negde ispod površine i da je zapravo književno delo neka vrsta zatvorenog entiteta koja za cilj ima da prenese određenu poruku čitaocu. Međutim današnje teoretsko stanovište smatra da je tekst otvorena struktura, ispunjena beskonačnim značenjima, a da sam čin čitanja podrazumeva trenutak kontekstualizacije (Réka, 2008: 46). Samim tim nameće se pitanje čemu film treba da ostane veran? Da li režiser mora ostati veran zapletu do poslednjeg detalja? U tom slučaju filmska verzija Rata i mira trajala bi 
trideset sati. Ili pak režiser mora da se povinuje „namerama“ autora? Stem kaže da bi to stvorilo nove probleme:

Autori često maskiraju svoje namere iz ličnih ili psihoanalitičkih razloga ili pak spoljnih razloga ili cenzure. Autorove izražene namere ne moraju biti od značaja, imajući u vidu upozorenja književnih kritičara na „pogrešne namere”, te nas podstiču da ,verujemo priči a ne pripovedaču”. Prust nas je naučio da autor nije važna sveprisutna individua već „un autre moi (moje drugo ja)”. Autori često i nisu svesni svojih najdubljih namera. Kako onda filmski tvorci mogu da im budu verni? (Réka, 2008: 47)

Stoga nasuprot ideji vernosti književnom izvoru, Stem predlaže alternativni pristup analizama filmskih adaptacija. On uvodi termin intertekstualnog dijalogizma u kritički diskurs, potpuno prebacujući fokus na književni i filmski tekst (2008: 47). On objašnjava da intertekst znači da „svaki tekst formira ukrštanje tekstualnih površina, pošto su svi tekstovi sastavni deo anonimne formule, varijacije tih formula, svesni ili nesvesni citati, spajanje ili inverzija drugih tekstova“ (2008: 47). Pozivajući se na Bahtina, Stem smatra da ne treba ograničavati koncept na isključivo jedan medij jer su svi tekstovi proizvodi ,beskonačnih i otvorenih mogućnosti koje proizilaze iz širokih delovanja kulture, čitava matrica komunikativnih veština u čijim okvirima se nalazi umetnički tekst"“ (2008: 47). Stem smatra da filmske adaptacije nisu ,isključivo vrsta višeslojnih pregovora intertekstova već se i sami nalaze u vrtlogu intertekstualnih referenci i transformacija, ili tekstova koji stvaraju druge tekstove u beskrajnom procesu reciklaže, transformacije, transmutacije, bez jasnog porekla“ (2008: 47).

U teoriji adaptacije postoje mišljenja da adaptacija može zauzeti i aktivan odnos prema izvornom romanu i postati deo šireg intertekstualnog dijalogizma koji podrazumeva da se svi tekstovi međusobno ukrštaju. Tekstovi su delovi formula, njihove varijacije, svesni i nesvesni citati, spoj ili pak inverzija drugih tekstova. Intertekstualni dijalogizam stoga pruža beskonačne mogućnosti nastanka i razvoja umetničkog teksta kao produkta kulturološkog diskursa (Stam, 2000: 64). Bahtin je pristupao intertekstualnosti kao kompleksnom i višedimenzijalnom dijalogizmu, koji je svoje korene imao u istorijskom kontekstu i društvenom životu, što je uticalo na razvoj književnosti kao kulturološkog fenomena. Bahtin smatra da se književnost kao i film mora proučavati unutar ,raznolikosti jedinstva čitave kulture jedne epohe“ (2000: 65). 
Pozivajući se na terminologiju Bahtina i Džulije Kristeve (Julia Kristeva), Žerar Ženet (Gérard Genette) u svom delu Palimpsesti (Palimpsests) iz 1982. godine gradi svoju teoriju o transtekstualnosti koja zapravo svaki tekst dovodi u vezu sa nekim drugim tekstom. Ona obuhvata pet kategorija:

1) intertekst - prisustvo jednog teksta u drugom što podrazumeva citiranje, plagijat, aluziju. Adaptacija je u ovom smislu dupli intertekst jer se zasniva kako na književnom tekstu tako i na filmskom;

2) paratekst - skup tekstova koji okružuju glavni tekst: naslovi, podnaslovi, predgovori, pogovori, fusnote, ilustracije itd;

3) metatekst - komentar nekog teksta ili kritički osvrt;

4) arhitekst - skup opštih, generičkih kategorija, tipovi diskursa, načini iskazivanja, književni žanrovi koji nisu određeni već ih klasifikuju čitaoci, kritika i publika;

5) hipertekstualnost - hipertekst se zasniva na hipotekstu koga potom transformiše, modifikuje, elaborira ili proširuje (2000: 65 - 66).

Filmske adaptacije se mogu posmatrati kao hipertekstovi izvedeni od već postojećih hipotekstova, koji se transformišu samim postupkom selekcije, proširivanja, konkretizacije i aktualizacije, stoga, možemo zaključiti da su filmske adaptacije neprekidan niz intertekstualnih referenci i transformacija jer svaki filmski tekst zapravo proizvodi nove tekstove. (2000: 66).

Stem polazi sa stanovišta da se filmske adaptacije mogu posmatrati kao transformacije hipoteksta izvornog romana koja se može odvijati na više različitih načina kao što su: selekcija, proširivanje, konkretizacija, aktualizacija, kritika, analogizacija, popularizacija i rekulturalizacija (2000: 68). Roman kao izvorni tekst može se posmatrati kao izraz jednog medija $\mathrm{u}$ određenom istorijskom kontekstu, koji je transformisan u drugi izraz, to jest filmsku adaptaciju, koja nastaje u drugačijem kontekstu i u različitom mediju (2000: 68). Filmske adaptacije romana vrše transformacije u skladu sa zahtevima novog medija, pri čemu u skladu sa diskursom i određenim ideologijama, pojedine intertekstove usvajaju ili pak menjaju usklađujući ih sa politikom filmskog studija, određenom ideologijom, političkim ograničenjima, autorskom pristrasnošću, harizmom filmskih zvezda, ekonomskim prednostima i razvojem tehnologije (2000: 69). Stoga, možemo zaključiti da se filmski hipertekst transformiše u skladu sa mnogobrojnim napomenutim faktorima.

Stoga Stem smatra da oni koji se bave analizom filmskih adaptacija moraju zadržati svoj kritički stav i imati slobodu u vrednovanju filmskih ostvarenja ali da filmske adaptacije ne možemo posmatrati površno, sa 
nekog moralističkog stanovišta, i pri tom sud zasnivati na nekoj vrsti hijerarhije po kojoj je roman uvek superiorniji u odnosu na film, već svoj sud moramo zasnivati na istorijskom i kulturološkom kontekstu i intertekstu (2000: 75). Takođe naša analiza ne treba da se zasniva isključivo na kritici „vernosti“" već na dijalogizmu koje podrazumeva tumačenja, kritike, interpretacije i transformacije prethodnog teksta. Ovakva vrsta kritike i analize može se smatrati svrsishodnom, jer ne samo da razmatra, već i uvažava razlike među medijima koje su neumitne.

Kristijan Reka smatra da za razliku od kritike vernosti koja ima za cilj da ukaže na ona mesta u filmu gde adaptacija odstupa od originalnog teksta, daleko veći značaj imao bi istovremeni pristup romanu i filmu, pri čemu bi uočene razlike između njih otvorile prostor za intertekstualni dijalog (Réka, 2008: 46). Na taj način književni i filmski tekst, nama koji se bavimo interpretacijom, otkrili bi svoje skrivene aspekte tako što bi filmska adaptacija pružila određene nove mogućnosti za interpretaciju romana i obrnuto, roman bi ,govorio“ o filmu (2008: 46). Teorijska osnova za ovakvu tvrdnju zasniva se na konceptu dijalogizma Mihaila Bahtina (ideje da je svaki izraz potencijalno u vezi sa svim drugim izrazima), kao i na filmskoj teoriji Roberta Stema.

\section{Filmski jezik i filmski narativ}

Tokom šezdesetih i sedamdesetih godina prošlog veka, filmski teoretičari pokušali su da oblikuju jezik koji bi odgovarao sistemu filma i samim tim objasnio šta se zapravo podrazumeva pod terminom filmski jezik. Filmski jezik je posebna vrsta jezika koji predstavlja „beskonačan način konstrukcije i rekonstrukcije sistema medijske komunikacije" (Réka, 2008: 35). Frančesko Kaseti (Francesco Casetti) smatra da se fraza filmski jezik odnosi na teorijsku tradiciju koja se pojavila pre Drugog svetskog rata, koja je razvila pristup bioskopu kao sredstvu komunikacije, to jest, „načinu koji omogućava čoveku da se izrazi i da deluje“"(2008: 35). Sredinom šezdesetih godina 20. veka nastaje novi semiotički pristup filmu, gde proučavanje lingvističkih osnova filma biva zamenjeno proučavanjem lingvističkih karakteristika“ (2008: 35). Razlika između ova dva pristupa ogleda se u tome što prvi pristupa lingvističkim analogijama kao nečemu što je prirodno i što se podrazumeva, dok drugi istražuje ,specifične komponente šireg fenomena“" (2008: 35). Stoga analiza filmskog jezika sagledava na koji način je mnoštvo 
komponenata organizovano u filmsku celinu, ili tačnije u filmski narativ.

Albert Lafaj (Albert Laffay) smatra da se bioskop zasniva na narativu jer je to jedini način ,da se realnost očita na platnu“ (2008: 35). Narativ je ključni element koji spaja različite komponente realnosti u jednu celinu, te stoga daje značenje tom svetu koji je prikazan na velikom platnu, pružajući mu logiku i vokabular, pretvara film u jezik; samim tim film dobija lingvistički fokus a istovremeno ulazi u kulturološke i umetničke okvire (2008: 36). Ako bismo pojam narativa definisali kao ,niz događaja u uzročno posledičnom odnosu koji se dešava u određenom vremenu i prostoru" shvatili bismo zbog čega narativni aspekti čine osnovu istraživanja filmova (2008: 36). Na formalnom nivou ističe se razlika između pojmova fabula i siže. Viktor Šklovski (Victor Shklovsky) ističe da je fabula (ili ,priča“"): „obrazac odnosa između likova i obrazac događaja koji se odvijaju hronološki“"(2008: 36). Fabula je i neka vrsta ,sirovog materijala“" koji tvorac filma pretvara u siže. Siže (ili ,zaplet") je zapravo prikaz priče: događaji ne moraju biti predstavljeni hronološki i reditelj ima slobodu da raznim sredstvima oblikuje fabulu u ,estetski zadovoljavajuću formu“" (2008: 36). Jedan od ključnih elemenata filmskog narativa je i tačka gledišta koja bi se mogla definisati kao perspektiva jednog od glavnih likova ili pak kao perspektiva naratora koji iznosi svoje viđenje likova i događaja u svetu fikcije (2008: 36).

Narativ sam po sebi predstavlja dublju strukturu koja je sasvim nezavisna od svog medija, drugim rečima, narativ je vrsta organizacije teksta koja se aktualizuje pisanom reči, kada su u pitanju romani ili pripovetke; ili govorom u kombinaciji sa pokretom glumaca, koji predstavljaju određene likove u određenom prostoru, kao što je slučaj sa dramom i filmom (Chatman, 1992: 403). Narativ ima i dvostruku vremensku strukturu. Svi narativi, bez obzira na medij, kombinuju vremenski tok događaja koji čini zaplet, sa vremenom predstavljanja tih događaja u tekstu koje nazivamo ,vreme diskursa“. Ova dva vremenska toka su međusobno nezavisna. Tako na primer kod realističnih narativa vremenski tok je hronološki i samim tim tok priče je nepromenjljiv, dok je vreme diskursa potpuno različito i često se, na primer, upotrebom flešbekova, može vraćati u različite vremenske periode (1992: 404).

Prilikom prevođenja narativa iz jednog u drugi medij, izmene su neminovne. Na primer deskriptivni odlomci u romanu, prelaskom na filmski medij, prikazani su vizuelno kroz slike. Filmski narativ obiluje vizuelnim detaljima koji su značajni kako bi nama gledaocima na pravi način preneli deskriptivnu sliku romana (1992: 407). Ponekad glas naratora, koji je prisutan u romanu, prenosi se i na film u obliku komentatora (takozvani „,voice-over"). Međutim ovakav režijski pristup često nailazi na negativne 
kritike, jer se pre svega polazi od stava, da film mora naći način da narativ predstavi vizuelnim sredstvima (1992: 408). Film ne opisuje, već vizuelnim sredstvima prikazuje i predstavlja određeni sadržaj uz pomoć kamere. Čest je slučaj da film započne dugim kadrovima koji zamenjuju deskriptivne odlomke romana i uspostavljaju određenu vizuelnu atmosferu.

Lafaj je neka vrsta preteče pokušaja da se film definiše kao jezik, da bi tokom šezdesetih i sedamdesetih godina 20. veka pojava takozvanog „filmsko-lingvističkog projekta“ za cilj imala da se studije filma baziraju na lingvistici i strukturalnoj semiotici (Réka, 2008: 37). Kristijan Mec (Christian Metz) u svom delu Filmski jezik (Film Language) stvorio je novu vrstu vokabulara za studije filma koji predstavlja kombinaciju tehničkog vokabulara lingvistike i naratologije zasnivajući svoj stav na idejama ruskih formalista da je: ,,bioskop sistem figurativnog jezika što znači da se filmski narativ sastoji od složene sintakse koja je sastavljena od fraza i rečenica“" (2008: 37). Ruska filmska škola je i pre nego što je strukturalizam postao deo filmske teorije, insistirala na ideji da filmski kadar, kao osnovni element filma, nema ,svoje suštinsko značenje dok ne postane deo strukture filmske montaže“ (2008: 38). Filmska montaža ima ključnu ulogu u povezivanju različitih fragmenata u jednu smislenu ritmičku celinu. Stoga Mec smatra da su kadrovi, za razliku od reči, neograničeni u broju, i nalik rečenicama, predstavljaju jedinice diskursa koje mogu biti formulisane u verbalni jezik (2008: 40). Mec kaže: ,govoriti nekim jezikom znači koristiti ga a govoriti kinematografskim jezikom u određenoj meri znači izumeti ga" (2008: 41). Film kao narativ sastoji se od raznih postupaka, te stoga, objekat semiotičke studije filma postaje dijegeza ili naracija kao takva, ali i drugi elementi kao što su vremenska dimenzija, likovi, pejzaži, događaji i slično, razmatraju se u svim svojim aspektima.

Maršal Koen (Marshall Cohen) pak smatra da kada je u pitanju stvaranje vizuelne slike, film i roman na isti način stvaraju verbalne i kinematografske znakove: ,,putem narativa koji je najčvršća veza između romana i filma, najprodornija težnja verbalnog i vizuelnog jezika. I u romanu i na filmu, grupa znakova, bilo pisanih ili vizuelnih, usvajaju se neprekidno kroz vreme, i taj neprekidni sled stvara otvorenu strukturu, dijegezu koja nikad nije sasvim prisutna ali je uvek implicirana u svakoj takvoj grupi““ (Andrew, 1992: 425). Narativni kodovi funkcionišu na nivou implikacije ili konotacije, stoga se može vršiti njihovo upoređivanje u romanu i na filmu. Priča se može podudarati ukoliko se određeni narativni elementi kao što su: likovi, događaji, motivi, posledice, konteksti, tačke gledišta, mogu naći kako u romanu tako i na filmu. Analiza adaptacije podrazumeva upoređivanje tih narativ- 
nih elemenata u dva različita semiotska sistema kao što su film i književni jezik. Ta vrsta analize takođe podrazumeva $\mathrm{i}$ ispitivanje filmskog stila određenog perioda $\mathrm{u}$ vezi sa književnim stilom drugog perioda (1992: 426).

Svako čitanje književnog teksta je individualni kognitivni čin interpretacije (McFarlane, 2007: 15). Film zahteva od nas, gledalaca, da sagledamo složenu interakciju mizanscene, montaže i zvuka, jer dok pisac sliku stvara uz pomoć reči, film nam je donosi kroz audio-vizuelna sredstva. Brajan Mekfarlan (Brian McFarlane) smatra da je narativ zajednički element književnosti i filma i da filmski narativ nije taj koji oduzima, već naprotiv, on je taj koji dopunjuje original svojim kulturološkim i kinematografskim elementima (McFarlane, 2007a: 5). Film poseduje svoje vlastite kodove kao što su: lingvistički kodovi (na primer akcenat ili način govora glumaca koji nam govore o raznim karakteristikama nekog lika kao što je njegova klasna ili etnička pripadnost ili pak temperament), nelingvistički kodovi (muzički i zvučni efekti), vizuelni kodovi (dok gledamo mi istovremeno interpretiramo ono što vidimo) i kulturološki kodovi (kostim i dekor) (2007: 20).

Ono što je zajedničko filmu i romanu je što oba medija stvaraju realistične živote i svetove. Pisac romana stvara svoje likove rečima koji ili oni sami izgovaraju ili pak drugi likovi govore o njima, koristeći i druge elemente poput misli ili unutrašnjeg dijaloga. Film čini to isto ali upotrebom različitih kodova. On se ne oslanja isključivo na reči, to jest dijalog, već i na gestikulaciju i druge zvučne elemente poput muzike. Vrlo često se filmu zamera da je teatralan ukoliko se previše oslanja na dijalog umesto na vizuelna sredstva. Međutim, upotreba dijaloga na filmu ne može se po automatizmu smatrati kinematografskim nedostatkom; koliko je on uspešno izveden zavisiće pre svega od glumaca i od režisera (2007: 25).

Kada govorimo o procesu adaptacije književnog narativa u filmski, zbog složenosti strukturalnih filmskih komponenata, uviđamo da proces transpozicije nije nimalo jednostavan. Upotreba filmskog jezika svakako nameće i problem prevođenja, to jest postavlja se pitanje ukoliko se rečenice mogu prevesti sa jednog jezika na drugi, da li je isto tako moguće prevesti književno delo na jezik filma?

\section{Prevod i filmska adaptacija}

Prevod i adaptacija, i kao proces i kao proizvod, su sastavni deo političkih i kulturnih dešavanja kako na globalnom tako i na lokalnom 
planu. Prevod igra ključnu ulogu u našem razumevanju ideologija, politike ili kulture, jer se kroz njega izražavaju određeni stavovi. Slično je i sa adaptacijom koja nam na isti način pruža uvid u političke i kulturne prilike društva u kome nastaje (Krebs, 2014: 1). Prevod i adaptacija zasnivaju se na analizi velikog korpusa materijala koji se sastoji od novinskih članaka, vladinih izjava, književnosti i raznih istorijskih i savremenih konflikata, koji u sebi sadrže primere prevođenja, što u različitom kontekstu može da se posmatra i kao čin adaptacije, to jest, ponovnog pisanja određenog teksta (2014: 1). Postoji snažan međusobni uticaj između procesa prevođenja i adaptacije s jedne strane, i kulture i politike s druge strane. Čitava popularna kultura sadašnjice se prvenstveno temelji na fenomenu adaptacije koji je doprineo procvatu filmske industrije ali i razvoju drugih medija, od pozorišta, mjuzikla i opere, pa do televizije (2014: 2).

Prevod i adaptaciju možemo posmatrati kao kreativan proces, ali i kao proizvod i artefakt, dok kao akademske discipline, one su po samoj svojoj prirodi interdisciplinarne (2014: 3). Obe se bave fenomenom kulturološkog prikaza kroz proces ponovnog pisanja i obe se suočavaju sa problemom autorstva u čemu se ogleda njihova sličnost (2014: 3).

Postoje određeni stavovi koji podvlače jasnu granicu između prevoda i adaptacije, smatrajući adaptaciju kreativnim procesom ponovnog pisanja i komentarisanja izvornog teksta, nasuprot prevodu koji prvenstveno teži da ostane jednak originalu (2014: 3). Adaptaciji se pripisuje kreativna sloboda, nasuprot prevođenju koje poštuje lingvistička ograničenja, ali zato ostaje veran originalnom tekstu. Studije adaptacije, za razliku od ranih teorijskih stavova, više se ne zasnivaju na modelu jednakosti i vernosti originalu. Džuli Sanders smatra da su adaptacije "ponovne interpretacije određenih tekstova u novom generičkom kontekstu i da one premeštanjem kulturnih i vremenskih prilika izvornog teksta mogu i ne moraju dovesti do opštih promena“"(2014: 3). Adaptacije su poput ,živih organizama koji žive u kohabitaciji sa drugim kulturnim i društvenim sistemima“"(2014: 4).

Međutim studije adaptacije i studije prevođenja mogu se međusobno dopunjavati po pitanju praktičnih i teorijskih pitanja, terminologije, metodologije i perspektiva, imajući u vidu da neki teoretičari filmsku adaptaciju posmatraju kao vid ,prevođenja“ ili čak ,transpozicije“ književnog sadržaja na ekran, čime ona zalazi u oblast intertekstualnosti i intermedijalnosti (2014: 6).

Postavlja se pitanje: šta je adaptacija? U kom kontekstu se ona koristi i definiše? Ako je definišemo nasuprot drugog koncepta da li je to prevod, prisvajanje, verzija, transpozicija, transformacija, parafraza, pa- 
rodija, aluzija, intertekstualnost? Da li se adaptacija pojavljuje kao termin prevodilačkog diskursa? (Minier, 2014: 15) Da li adaptacija predstavlja ponovno ispisivanje prisvojenog teksta gde istovremeno autorizuje i kritikuje određene ideološke stavove? (2014: 16).

Adaptacija predstavlja prilagođavanje, podrazumevajući često neophodno unošenje izmena u odnosu na izvorni tekst, kako bi se on prilagodio različitom kontekstu i ukusima publike (Minier, 2014: 16). Dejvid Lein (David Lane) smatra da je adaptacija transpozicija originalnog teksta u različit kontekst koji se mora sagledati na tri načina: Prvi je kontekst medija, na primer, transpozicija romana u filmski medij. Drugi je kontekst priče originalnog teksta, na primer, u kakvom svetu žive glavni likovi romana. Treći kontekst je izvan medija ili priče originalnog teksta i bavi se vremenom i mestom u kome živi publika koja se susreće sa adaptacijom (2014: 17). Fišlin (Fischlin) smatra da adaptacija poput prevođenja, predstavlja kulturnu aktivnost, koja deluje u novom kontekstu i stoga pruža veći doprinos kulturnom razvoju (2014: 17).

Adaptaciju je teško definisati bez obzira da li se akcenat stavlja na proces, proizvod, strategiju ili kontekst. U ovom radu se bavimo adaptacijom kao „procesom kojim tekst dobija vizuelni prikaz na ekranu“ (2014: 17), stavljajući akcenat na filmsku adaptaciju romana, dok sam pojam obuhvata daleko širi dijapazon medija; jer koncept adaptacije predstavlja transfer sa jednog umetničkog medija na drugi. Linda Hačen adaptaciju poredi sa prevođenjem, a takođe i Andre Bazen (André Bazin) koristi metaforu prevođenja kada govori o odnosu filma i adaptiranog teksta (2014: 19). 1992. godine lingvista Jakobson uvodi dva termina intralingvalni prevod (intralingual translation) za doslovno prevođenje teksta i intersemiotski prevod (intersemiotic translation) za prevođenje verbalnih znakova u neverbalni sistem, što podrazumeva promenu medija, kao što je prevođenje verbalne umetnosti u medij muzike, slikarstva ili filma (2014: 20). Ovi termini odgovaraju terminu adaptacije koju mi danas koristimo u savremenom diskursu.

Studije prevođenja svakako pružaju osnov za razvoj teorije filmske adaptacije ali se pri tom, kako smatra Džejms Naremor (James Naremore), mora voditi računa da se ne insistira na teoriji vernosti originalnom tekstu kao dominantnom kritičkom pristupu adaptaciji (2014: 20). Barton Palmer (Barton Palmer), međutim, odbacuje termin prevođenja, smatrajući ga interlingvalnim procesom koji se previše vezuje za izvorni tekst. 1982. godine Andre Lefever (André Lefevere) uvodi pojam refrakcije (refraction) dovodeći u pitanje validnost kritike vernosti. On staje u odbranu od negativnih 
kritika koje na filmske adaptacije gledaju kao na „neoriginalna“ dela. Uvodeći termin refrakcije to jest prelamanja, on objašnjava na koji način se tekst ponovo ispisuje kako bi se uskladio sa potrebama određene publike. On se suprotstavlja onim stavovima koji originalni tekst uzimaju kao neprikosnoveni autoritet koji se mora doslovno pratiti u svakom procesu prevođenja, objašnjavajući da su svi tekstovi zapravo prelamanja, i da adaptacija opravdava vrstu prilagođavanja do koje mora doći kako bi se uskladila sa ideološkim i estetskim zahtevima publike kojoj se obraća (2014: 21).

Linda Kahir smatra: ,da je prvi korak u istraživanju zasluga filmova zasnovanih na književnosti, posmatrati ih kao prevode izvornog materijala i razumeti razliku između adaptacije i prevoda" (2014: 21). Ona definiše pojam adaptacije i prevoda na sledeći način:

Dok se filmovi zasnovani na književnosti, uobičajeno i razumljivo, nazivaju adaptacijama, termin 'adaptirati' znači promeniti strukturu i funkciju jednog entiteta kako bi lakše preživeo i množio se u novoj sredini. Adaptirati znači pomeriti taj isti entitet $u$ novu sredinu. $U$ procesu adaptacije, taj isti nezavisni entitet koji je ušao u taj proces opstaje, iako je podvrgnut modifikacijama - ponekad radikalnim mutacijama - u naporima da se prilagodi svojoj novoj sredini (Minier, 2014: 21).

Termin 'prevesti' nasuprot 'adaptirati', znači preneti tekst sa jednog jezika na drugi. To je proces jezika, a ne proces opstanka i rađanja. Kroz proces prevoda potpuno novi tekst - materijalno različit entitet - se stvara, koji istovremeno ima čvrst odnos sa originalnim izvorom, a ipak je potpuno nezavisan od njega. Jednostavno rečeno: mi možemo da uživamo u prevodu bez čitanja originalnog izvora. Ako filmove zasnovane na književnosti posmatramo kao prevode, mi ćemo uvideti da njihovi tvorci prenose jezik književnosti - koji se sastoji od reči - na jezik filma... U tom procesu, oni prave izbor unutar filmske sintakse i vokabulara (2014: 21).

Važno je naglasiti da adaptacija podrazumeva postavljanje nekog dela u ,novu sredinu“ što podrazumeva novi kulturni i lingvistički kontekst. Kahir takođe smatra da prevođenjem književnog teksta na neki drugi jezik, vernost prevoda igra ključnu ulogu mada je pitanje vernosti kompleksno. Ona takođe komentariše: ,ponekad je film loš prevod književnosti“ (2014: 22). Dezmond (Desmond) i Hoks (Hawkes) smatraju da je besmisleno porediti izvorno delo i adaptaciju po modelu, ,vernosti“ jer se sistematski i strukturalno razlikuju te stoga ne mogu biti identične. Linda Hačen insistira na kontekstualnim elementima procesa adaptacije odbacujući model „vernosti“.

Poststrukturalistički diskurs ne posmatra prevod kao simetriju između dva teksta koji se zasniva na idiomu ,vernosti“ i ne pristupa prevodu 
kao procesu oponašanja originalnog teksta jer je on sam po sebi čin posredovanja i ponovnog predstavljanja. Pri tom je važno napomenuti da on nastaje i oblikuje se u okvirima specifičnog kulturnog konteksta. Adaptacija kao oblik prevođenja, prevodi reči u slike, romane u filmove, pri čemu se susreće sa velikim estetskim izazovima jer prenosi sadržaj jednog u drugi medij koji se suštinski razlikuju. Često sam čin vizuelnog predstavljanja može naići na određene tabue i zabrane (Elliott, 2004: 16).

$\mathrm{Na}$ osnovu analize teorijskih pristupa adaptaciji kao slobodnom prevodu postojećeg teksta na nove jezike, kritički zaključujemo da adaptacija predstavlja stvaralački proces, koji sam po sebi podrazumeva novu interpretaciju i čin stvaranja novog umetničkog dela. U tom stvaralačkom procesu osnovna premisa je da se sačuva priča preuzeta iz originalnog književnog dela ali da se njoj istovremeno udahne novo viđenje koje će uspešno komunicirati sa publikom. Adaptacija je forma intertekstualnosti. Ona je višeslojna i u sebi nosi kako repeticiju originalnog izvornog teksta tako i varijacije novog umetničkog stvaralaštva.

\section{Literatura}

Andrew, D. (1992). From Concepts In Film Theory: Adaptation. In Mast, G. \& Cohen, M. (ed.). Film Theory and Criticism: Introductory Readings (pp. 420-428). Oxford: Oxford University Press.

Chatman, S. (1992). What Novels Can Do That Films Can't (and Vice Versa). In Mast, G. \& Cohen, M. (ed.), Film Theory and Criticism: Introductory Readings (pp. 403-419). Oxford: Oxford University Press.

Cutchins, D. (2014). Bakhtin, Translation and Adaptation. In Krebs, K. (ed.) Translation and Adaptation in Theatre and Film (pp. 36-59). New York: Routledge.

Elliott, K. (2004). Novels, Films, and the Word/Image Wars. In Stam, R. \& Raengo, A. (ed.) A Companion to Literature and Film (pp. 1-22). USA: Blackwell Publishing Ltd.

Krebs, K. (2014). Introduction: Collisions, Diversions, and Meeting Points. In Krebs, K. (ed.) Translation and Adaptation in Theatre and Film (pp. 1-12). New York: Routledge.

Leitch, T. (2012). Adaptation and Intertextuality, or, What isn't an Adaptation, and What Does it Matter? In Cartmell, D. (ed.) A Companion to Literature, Film, and Adaptation (pp. 87-104). West Sussex: Blackwell Publishing Ltd.

McFarlane, B. (2007a). It Wasn't Like That in the Book. In Welsh, J.M. \& Lev, P. (ed.). The Literature/Film Reader: Issues of Adaptation (pp. 3-15). USA: Scarecrow Press, Inc. 
McFarlane, B. (2007). Reading film and Literature. In The Cambridge Companion to Literature on Screen (pp. 15-28). Cambridge: Cambridge University Press.

Minier, M. (2014). Definitions, Dyads, Triads and Other Points of Connection in Translation and Adaptation Discourse. In Krebs, K. (ed.) Translation and Adaptation in Theatre and Film (pp. 13-35). New York: Routledge.

Réka, M.C. \& Zoltan, D. (2008). Do You Speak Film?: Film Language and Adaptation. In Encounters of the Filmic Kind: Guidebook to Film Theories (pp. 35-49). Szeged: Szegedi Egyetemi Kiado.

Stam, R. (2000). Beyond Fidelity: The Dialogics of Adaptation. In Naremore, J. (ed.) Film Adaptation (pp. 54-76). New Jersey: Rutgers University Press.

\section{Izvori}

Boozer, J. (2008). Authorship in Film Adaptation. Austin: University of Texas Press.

Cardwell, S. (2007). Adaptation Studies Revisited: Purposes, Perspectives, and Inspiration. In Welsh, J.M. \& Lev, P. (ed.). The Literature/Film Reader: Issues of Adaptation (pp. 51-64). USA: Scarecrow Press, Inc.

Cartmell, D. \& Whelehan, I. (2007). Introduction - Literature on screen: a synoptic view. In The Cambridge Companion to Literature on Screen (pp. 1-13). Cambridge: Cambridge University Press.

Cartmell, D. (2012). 100+ Years of Adaptations, or, Adaptation as the Art Form of Democracy. In Cartmell, D. (ed.) A Companion to Literature, Film, and Adaptation (pp. 1-15). West Sussex: Blackwell Publishing Ltd.

Casetti, F. (2004). Adaptation and Mis-adaptations: Film, Literature, and Social Discourses. In Stam, R. \& Raengo, A. (ed.) A Companion to Literature and Film (pp. 81-91). USA: Blackwell Publishing Ltd.

Cobb, S. (2012). Film Authorship and Adaptation. In Cartmell, D. (ed.) A Companion to Literature, Film, and Adaptation (pp. 105-121). West Sussex: Blackwell Publishing Ltd.

Corrigan, T. (2007). Literature on screen, a history: in the gap. In The Cambridge Companion to Literature on Screen (pp. 29-44). Cambridge: Cambridge University Press.

Halliwell, M. (2007). Modernism and adaptation. In The Cambridge Companion to Literature on Screen (pp. 90-106). Cambridge: Cambridge University Press.

Hutcheon, L. (2006). A Theory of Adaptation. New York: Routledge.

Leitch, T. (2007). Film Adaptation and Its Discontents: From Gone with the Wind to The Passion of the Christ. Baltimore: The Johns Hopkins University Press. 
Meskin, A. (2009). Authorship. In Livingstone, P. \& Plantinga, C. (ed.). The Routledge Companion to Philosophy and Film (pp. 12-26). London and New York: Routledge.

Murray, S. (2012). The Business of Adaptation: Reading the Market. In Cartmell, D. (ed.) A Companion to Literature, Film, and Adaptation (pp. 122-140). West Sussex: Blackwell Publishing Ltd.

Petrić, V. (1970). Razvoj filmskih vrsta. Beograd: Umetnička Akademija u Beogradu. Snyder, M.H. (2011). Analyzing Literature-to-Film Adaptations: A Novelist's Exploration and guide. New York: The Continuum International Publishing Group.

Ana Mandić Ivković

\section{Summary}

\section{ADAPTATION AND INTERTEXTUALITY}

In film adaptation studies, the theory of intertextuality is gaining in importance, especially in the last two decades. This work is based on a theoretical approach to film adaptation, where the theories of Thomas Leitch, Linda Hutcheon, Robert Stam, Christian Metz, Brian McFarlane, Linda Cahir, Katja Krebs and other significant theorists are analyzed. This paper analyzes the relationship between the adaptation process and the translation process, and concludes that film art has its own film language and film narrative, since film, as well as a literary work, also tells the story just using different means of expression. Adaptation makes certain ideas actual, creates analogies, expresses criticism or indicates respect for the original text. We consider adaptation as a formal entity and as a transposition of a particular literary work, bearing in mind the change of media, possible change of genre, change of context or a different point of view within the new interpretation. We analyze the theoretical approach to adaptation as a free translation of the existing text into new languages, and we critically conclude that adaptation is a creative process, which in itself implies a new interpretation and an act of creating a new artwork. In this creative process, the basic premise is to preserve a story taken from the original literary work, but at the same time to breathe new vision, which will successfully communicate with the audience. Adaptation is a form of intertextuality. It is multilayered and in itself carries the repetition of the original text as well as the variation of the new artistic creativity.

Key words: intertextuality, film language, translation 